\title{
Research on Electricity Market Management System based on Lean Theory
}

\author{
Zhiming Wang \\ Jinzhou Power Supply Branch \\ State Grid Liaoning Electric Power Supply Co. Ltd \\ Jinzhou, China \\ e-mail: wangzhimingjz@163.com
}

Lei Zhou

Jinzhou Power Supply Branch

State Grid Liaoning Electric Power Supply Co. Ltd Jinzhou, China

e-mail: zhouleijz@163.com

\author{
Feng Yin \\ Jinzhou Power Supply Branch \\ State Grid Liaoning Electric Power Supply Co. Ltd \\ Jinzhou, China \\ e-mail: yinfengjz@163.com
}

\begin{abstract}
There are two big problems in the market now. First, the power products of power grid enterprises can not be stored, but marketing and supply of production complete with one-time instantaneous. Second, the power grid enterprises do not produce, the procurement price of electric products is determined by the state, and does not involve the problems of product and product management, so management of the power market is the core and key process of power market operation. Therefore, by strengthening management and operation of electricity market, it plays a vital role in promoting sustainable management and development in the electricity market management and operation to improve the operational efficiency and entire firm. According to Chinese electricity market planning and the actual situation in Liaoning, we establish long-term development planning that we use the lean production methods to improve the management level of power market, improve service quality, enhance the economic efficiency of enterprises for improving the performance of the company.
\end{abstract}

Keywords- stored; marketing; supply; planning; lean

\section{INTRODUCTION}

Lean production is a new mode of production, is born in the Toyota Auto Body Co of Japan after the second single and mass production methods. Toyota Corporation Toyoda Kiichiro, Toyoda Eiji and Ono Chi after 20 years of reformation, realizes to produce TOYOTA system of reducing waste to many varieties, the main purpose of the small batch, high quality and low consumption. The American scholars called "lean production", in the global spread and application. Lean production for the traditional mode of production, is a kind of great change, it is in the lean management under the guidance of thinking, to "just in time JUST IN TIME" and "automation" as the mainstay, standardization, smooth, improve as the basis, by means of "5S" and "Kanban", "comprehensive quality management, benchmarking management tools such as the formation of a production management model [1].

Lean production means that we apply "lean thinking" concept to the activities of enterprises. "The core of lean thinking is that the people create the value as much as possible by costing the minimum input of resources, including manpower, equipment, funds, materials, time and space to offer new products and timely service for customers. This idea can be applied in electric power market.

James Womack and Daniel Jones propose five principles from their brilliant book "lean thinking", namely: Customer value, Value stream mapping, Value flow, Pulling perfect, Perfection. The core idea of lean management can be summarized to create value and eliminate waste [2].

Customer value is determined by the customer's point of view to determine the enterprise from design to production to the whole process of delivery, the maximum to meet customer demand.

Value stream is all giving value to it from raw materials into finished product. The meaning of identification of lean thinking value stream frome the value stream find that what is the real value-added activities can be immediately remove the non value-added activities.

Lean thinking requires the activities of the creation of value (step) flow, emphasizes the uninterrupted flow".

"Pull" is inputs and outputs according to the customer demand, the user get the required at the time when they are needed.

Continuous that through flow analysis method find out more hidden waste value, then further improvement.

Benign cycle tends to perfect such as. 


\section{THE DEVELOPMENT PLAN OF CHINA ELECTRIC POWER MARKET}

In future the overall structure of development of China electric market can be divided into two stages. Initial stage is divided into three levels, namely, the national electricity market, regional electric power market and provincial power market,and three power market operation mode to country, region, province (city) level. The second stage, gradually strengthen the grid market of large area, combine the power market into a regional power market, the final transition to two level power market of the national and regional.

The electricity market is based on the national network, cross-regional power trading market[3]. The regional power grid, the provincial network companies and independent country adjust straightening power plant as the main body of the market, using market mechanism, making full use of different resources of allocation difference and time difference, the difference of climate and the peak and valley regions, realization of power resources among regions, accident support, spare sharing etc. In the safe and stable operation of power grid, the goal is to adjust the surplus and deficiency in the national scope, and giving full play to benefit of the national power grid interconnection, realize the optimal allocation of electric resources nationwide.

Regional electricity market is based on the regional power grid, is responsible for electricity trade within the region and to achieve the optimal allocation of power resources in the whole area, is the key of power market construction in china[3]. Each regional electricity market is open to the national electricity market and accepting the power of national electric power market, and implemente close coordination with the provincial power market. The goal is to break down the barriers existing between the province to a certain extent, and to construct a unified, open, competitive and orderly regional electricity markets.

Provincial power market is the key level of power market in China at present stage. Provincial power market put the provincial network as the carrier, market mode can be determined according to the area and the economic development of the province and the grid condition in the specific circumstances [4]. In the part of the regional, provincial power market is based on regional power market, and the regional power market is a joint body, complete power market transactions in their mutual coordination and close cooperation.

In the primary stage of the formation of the electricity market, the cultivation and growth of provincial power market is the recent focus of the reformation and the construction of electric power market, establishing and developing regional electricity market on existing provincial power market. While the long-term goal of the Chinese power market is the national electricity market that establish a unified, open, competitive and orderly closely connection, regional grid electricity markets will merge the province electric power market and become a very important role in power market. Gradually the construction and development of the above three levels of power market constitute the organic whole of power market in china.

\section{ANALYSIS OF LIAONING ELECTRIC POWER COMPANY COMPETITIVE ENVIRONMENT}

According to Mike.Potter's theory, first, the basic factor of determining the profitability of an enterprise is the profitability of the industry, and the profitability of the whole industry is determined by five factors: potentialentrants, Substitutes, power of buyer, power of suppliers and rivalry.

The analysis of these five elements is also an analysis of the market's main body. According to the Potter five forces model of competition and marketing of Liaoning electric power company's actual situation, can analysis Liaoning electric company from the four aspects in competition environment.

\section{A. Energy alternatives' analysis}

There is no alternative to the competition of the products in the same industry at the present stage in the Liaoning electric power company, but there is other alternative energy competition. In energy consumption market fierce competition continue from coal, oil, gas, solar energy and power supply enterprises. The main rival energy competition of Liaoning electric power company is Gas Co and the supply of coal enterprises. Among them, in the area where environmental protection require higher and control more strict, residents face of household heating, food industry and where the major competitors is the Gas Co, where environmental protection requirements are relatively low in rural areas, the main competitors is the supply of coal enterprises. In the final energy consumption market, coal has accounted for a large proportion, but compared to other energy. The combustion process will emit large amounts of carbon dioxide, dust, then after burning cinder pile will occupy the site, the damage to the ecological environment is very serious, and the burning efficiency is low[5]. Therefore, the market competitiveness of coal will be small. At the same time, with the rising price of coal and fuel oil, and coal, fuel and other alternative energy competition tends to favor, electric energy is a clean and efficient, economic, ring energy will become more obvious advantages.

\section{B. Supplier analysis}

The current implementation of "bidding" principle, is advantageous for power supply enterprises, can carry out procurement to relatively cheap power. But currently the government implement the direct supply mode to large customers in power generation enterprises, raise bargaining ability of the power supply enterprise. For power enterprises, power market bidding, relative surplus in power enterprises and power grid, ability of the supplier's bargaining become high. Along with the pilot and promote the pattern of direct power purchase for UHV trans provincial grid fully completed and large users, power generation enterprises may apply power to the power grid of power shortage and some large users, improve the power generation enterprise bargaining power of Power Grid Corp[6].

\section{Analysis of potential competitors}

Potential competitors include electricity power stations of directly purchasing electricity and the corporate of owned power plant [7]. In front, the supplier analysis 
mentioned who in the pattern of direct power purchase customers, part of the electric enterprises will participate in the sale of electricity to the user of the competition, become a rival power potential. Liaoning electric power company is both an opportunity and a threat, on the one hand, large consumers of direct purchasing of electric energy can increase electric quantity of the area network sale, make the enterprise use more electricity, reduce the purchase of electricity and electricity cost; on the other hand, because competition between electric power enterprises and the enterprises of the sale of electricity, will cause the price cut, make the Liaoning electric power company reduce the sale of electricity price.

\section{Analysis of power user's bargaining power}

For the power enterprise, it belongs to monopoly at present, buyers are almost no bargaining power, reform of power system is to change the status quo. In the future, there will be more than two power supply enterprise in a business area, the user can choose the power supplier, the bargaining power of customers will increase. The larger user can directly signe a purchase contract with the power companies, which enable bargaining power of the user greatly strengthen.Between the user's competition of power generation enterprises and the power supply enterprise will become appear soon after the promotion of large consumers direct purchasing mode and pilot in the separation of plant and network[8]. In short, marketing activities of the power company quickly adapt to the changing market environment, respond positively for dynamic process of the environment in a timely. Whether it can discover, understand and adapt to the new environment to avoid the risk of competition, related to future success or failure of the Liaoning electric power company's the development. Liaoning electric power company must fully consider the influence of environmental factors in the development of marketing strategies and measures[9].

\section{DESIGN OF LEAN POWER MARKET}

Preliminary ideas of Liaoning electricity market construction, based on the present situation, the construction target and long-term development planning, shown in Fig .1.

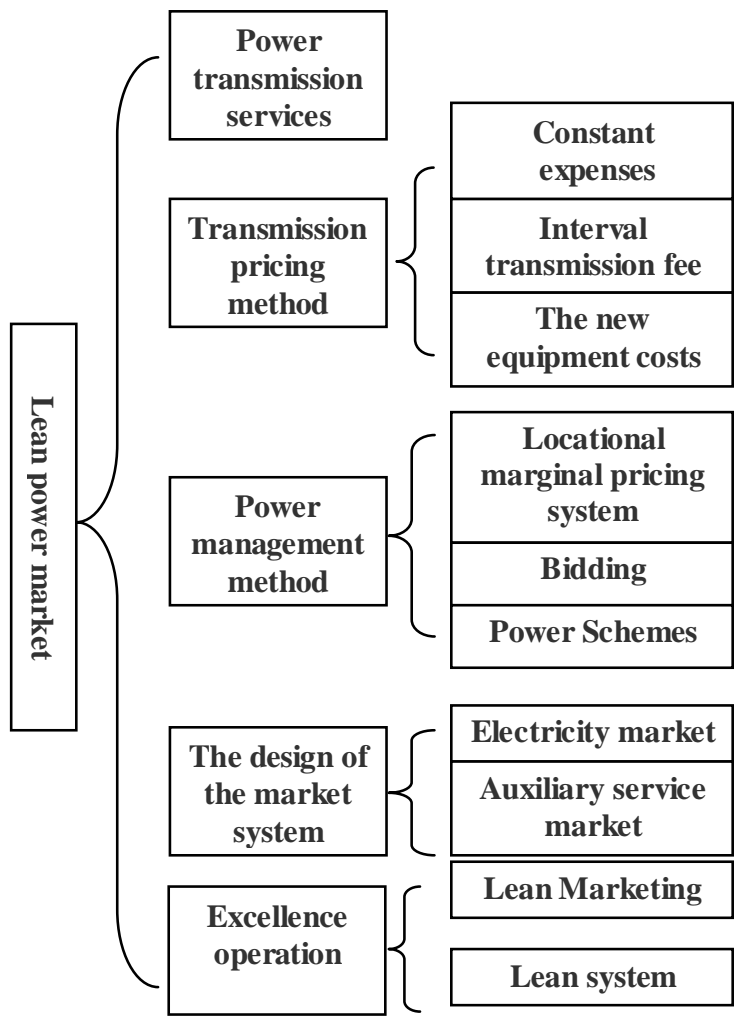

Figure 1 .Design of lean power market

This production management mode is not only widely used in manufacturing enterprises but also applied in other industries of electric power, chemical industry, service industry and other fields, and achieved good economic benefit10].

We use this method can largely improve the power efficiency, improve energy utilization results.

In the lean power market management, customer take up the main body, take the customer as the center, based on the value relation, establish the market management, to continuously improve building lean service system as the basis of lean lean, ensure the realization of power market, shown in Fig. 2 


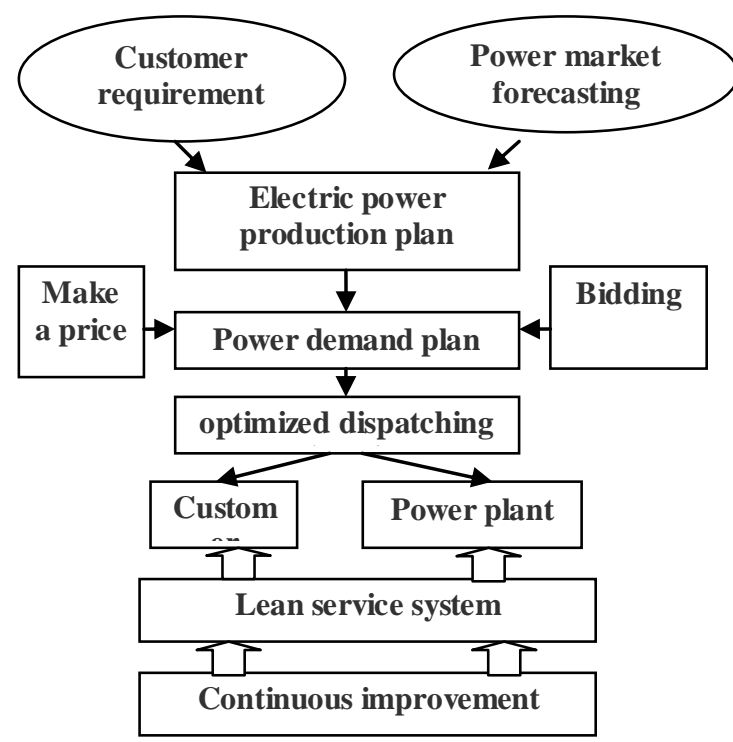

Figure 2. Lean management strategy of electric power market

\section{CONCLUSION}

Lean power market management is to adapt to the requirements of sustainable development about resource allocation methods and management methods, obtained the application in the electric power sector in many countries of market economy, and received the good effect in saving electricity, improving the energy consumption structure, improving the social consumption level, reducing power consumption, realizing power conservation and development simultaneously.

\section{ACKNOWLEDGMENT}

The authors gratefully acknowledge the contribution of co-workers and reviewers' comments.

\section{REFERENCES}

[1] J. An, "The research of safety culture construction of electric power enterprise,"Ele. Pow. Ent. Mant, vol. A247,pp. 40-42, April 2002

[2] J.Womack. "The machine change the world," Cam.Univ.Press, vol.6 ,pp.104-107, May 1999

[3] H.Lian,X.D.Zhao,and D.S.Zhang," Research on safety management of construction project in lean," Jou.Changsha.Dis.Voc.Tech.Co, vol. 2,pp.62-64,May 2010

[4] J.X.Ai and H.Feng, "Thinking on on the construction of safety culture in electric power enterprise," Elec.Saf.Tech, vol.8,pp. 18-20, May 2010

[5] S.Yuan, "Idea and strategy of lean management in power grid enterprise,"China.Ele.Pow, vol.7,pp.242-244, July 2010

[6] J.Zhu, "Application of lean management in power supply enterprises," China.Ele.Pow.Ent.Man,vol.5,pp.46-48,August 2006

[7] B.Wang,J.J.Jiang,C.Q.Kang ,and Q.Xia,“The main idea of design standard of American power market and the design of electric power market of China,"Pow.Sys.Tech,vol.3,pp.24-27, July 2004

[8] L.J.Xu, "Promoting the fine management significance of power supply enterprise," Sci.Tech.Inform.Dev.Eco.vol.14,pp.24-27, May 2010

[9] M.Zeng and G.Tian, "The analysis and design of the wholesale electricity market of Latin American countries and Its Enlightenment to China," China .Elec. Pow.News, vol.18,pp.8287, April 2009

[10] H.Li, "Electricity market design," Res.Refo.Econ.Theory, vol.37,pp.10-16, April 2008 